\title{
Dynamic Characteristics and Stability Analysis of Conical Relief Valve
}

\author{
Wenhua JIA*, Chenbo YIN**, Fei HAO***, Guo LI****, Xingzhi FAN***** \\ * School of Mechanical Engineering, Nanjing Institute of Technology, Jiangsu,China, E-mail: gevorml@163.com \\ ** School of Mechanical and Power Engineering, Nanjing University of Technology, Jiangsu,China, \\ E-mail: chbyin@163.com \\ *** School of Mechanical Engineering, Nanjing Institute of Technology, Jiangsu,China, E-mail: patrick_823357@163.com \\ **** School of Mechanical Engineering, Nanjing Institute of Technology, Jiangsu,China, E-mail: li_guo@163.com \\ ***** School of Mechanical Engineering, Nanjing Institute of Technology, Jiangsu,China, E-mail: 1954563303@qq.com \\ crossref http://dx.doi.org/10.5755/j01.mech.25.1.22881
}

\section{Nomenclature}

$P$ is pressure of fluid; $A$ is cross-sectional area of the tapered valve; $\rho$ is fluid density; $Q$ is flow rate of control; $C_{d}$ is discharge coefficient; $y$ is vertical distance; $D$ is Diameter of cylinder fluid; $K q$ is flow gain coefficient; $K c$ flow pressure gain factor; $m$ is valve core quality; $k$ is spring stiffness; $F_{S P}^{\prime}$ is spring preload; $F_{f}$ is fluid force; $P_{0}$ is pressure when the distance between conical; $A s$ is control fluid flow cross-sec area $A_{S}=\pi D^{2} / 4 ; \theta$ is jet angle; $F_{t}$ is transient fluid force acting on cone body power; $F_{s}$ is steady state fluid force; $F_{p}$ is pressure force for the flow field; $M_{\text {eff }}$ is effective mass of the spool; $C_{e f f}$ is effective damping coefficient of cylinder fluid; $K_{\text {eff }}$ is effective elastic modulus of the spring; $F_{d}$ is hydraulic resistance; $Y(s)$ is Laplace's formulas for the valve core dis; $P(s)$ is flow field pressure of the relief valve placement; $y_{0}$ is initial displacement; $V$ is large fluid volume; $\Lambda$ is stability factor.

\section{Introduction}

The control of flow, pressure, and fluid direction in hydraulic systems is realized via hydraulic control valves. The performance of valves determines the working state of the whole hydraulic system [1-4]. The cone valve has good sealing performance, rapid response, strong over-current capability, and strong anti-pollution capability. There is no dead zone when the valve opening is opened. The control stage and pilot stage of the hydraulic control valve mostly adopt the conical valve structure and become widely used hydraulic basic components. A conical direct-acting relief valve shown in Fig. 1. The conical valve is generally used in combination with a spring, which makes the conical relief valve often accompanied by intermittent large energy loss and frequent vibration and other issues, seriously affecting the structural stability, safety pressure protection and other functions of the relief valve. Whether its performance is good or bad has a very important influence on the performance of hydraulic systems and mechanical products.

Domestic and foreign scholars have studied the characteristics of hydraulic conical valves both experimentally and theoretically. Scholars used the finite element method to numerically calculate the internal flow field of the conical valve with different opening degrees [5, 6], different valve core structures, and different valve seat sizes, and studied valve port static flow characteristics of three representative structural feature throttling methods. Manring and Noah D et al. [4, 7] declared that the transient hydrodynamic forces acting on the valve are not negligible based on experimental results. R. Amirante et al. [8] analyzed the variation law of the flow coefficient at the throttle valve with the opening degree and discussed the steady-state hydraulic power and throttling stiffness characteristics of the valve port. Jia Wenhua et al. [9] analyzed the pressure control valve with a load sensing pressure compensation function to derive the nonlinear expression and analyzed the influence of the characteristic parameters on system stability. Jose'R and Valde's et al. [10] from Spain studied the accurate estimation of the valve flow at the core of conical valve. The flow field simulation method was used to analyze the characteristics of the flow velocity in the valve. The flow field simulation and theoretical analysis of the steady-state hydraulic power were also performed. The traditional flow calculation model and state stable fluid dynamics model of the hydraulic valve were revised. Some scholars also carried out a lot of flow field simulation researches [11-12]. Although the conical valve is only a single device, its flow characteristics are still theoretically difficult to predict, and its hydrodynamic forces are often ignored or simplified during modelling.

This paper makes full use of the characteristics of the box design. With the purpose of designing the conical relief valve structure, a nonlinear model is established to obtain the actual dynamic characteristics and stability criteria of the relief valve system. Regarding the intrinsic characteristics of the conical relief valve, the influence of design parameters on overflow stability and dynamic characteristics is analyzed.

\section{Conical relief valve system}

For the relief valve shown in Fig. 1, it has a conical valve core provided with a core seat support spring. The provided damping piston serves as a damping function when the conical valve is opened or closed, thereby improving the working stability of the conical valve. On the one hand, it is designed to ensure that the poppet valve will not tilt after opening. The inlet pressure oil $P$ forms a hydraulic pressure of $F_{f}=P A$. When this hydraulic pressure $F_{f}$ is greater than the spring force, the port of the conical valve is opened, and the oil flows from the conical valve port to the tank via the return port. As long as the valve port is open, there is oil flowing through the conical valve. If the designed relief valve system is stable, the pressure at the inlet of the conical valve 
is basically kept constant, and it can play a good role in constant pressure overflow, system unloading, and safety protection. Therefore, the structure of the cone body, the flow cylinder fluid, and the core seating parameters will all be important factors affecting the dynamic characteristics and stability of the relief valve.

The conical valve port opens, the fluid flows through the cylinder fluid, passes through the narrow gap between the cone and the core seat, and then returns to the tank. In this process, the opening of the valve is small, and the flow characteristics of the valve port are similar to those of the thin-walled orifice, and the flow formula ( $Q=A C_{d} \sqrt{2 P / \rho}$ ) of the thin-walled orifice can still be utilized.

$$
A=\pi\left(D(\sin \theta) y+(\cos \theta)\left(\sin ^{2} \theta\right) y^{2}\right) .
$$

According to the conical valve port shown in Fig. 1, $y / D<<1$ The second item in Eq. (1) can be ignored. i.e.

$$
A=\pi D(\sin \theta) y
$$

It is assumed that the fluid in the conical valve chamber has incompressibility and flow stability, and bubbles do not appear during the flow.

The flow model equation of the cylinder fluid expressed in Taylor expansion is shown in Eq. (3).

$$
\begin{aligned}
& Q=Q_{0}+\left.\frac{\partial Q}{\partial y}\right|_{0}\left(y-y_{0}\right)+ \\
& +\left.\frac{\partial Q}{\partial P}\right|_{0}\left(P-P_{0}\right)=Q_{0}+K_{q} \cdot \Delta y+K_{c} \cdot \Delta P,
\end{aligned}
$$

where: $K_{q}=\left.\frac{\partial Q}{\partial A} \frac{\partial A}{\partial y}\right|_{0}=\left.C_{d} \sqrt{\frac{2 P}{\rho}} \frac{\partial A}{\partial y}\right|_{0}$, $K_{c}=\left.\frac{\partial Q}{\partial P}\right|_{0}=\left.\frac{A}{\sqrt{2 \rho P_{0}}} C_{d}\right|_{0}$. By substituting Eq. (2) for the cross-sectional area of the cone valve port into, there is:

$$
\begin{aligned}
& K_{q}=\pi D(\sin \theta) P_{0} C_{d} \sqrt{2 P_{0} / \rho}, \\
& K_{c}=\pi D(\sin \theta) y_{0} C_{0} / \sqrt{2 \rho P_{0}} .
\end{aligned}
$$

In the opening of the conical valve, the cone is subjected to a pair of opposing forces, as shown in Fig. 2. One of the forces comes from the spring which drives the cone body closed and the other opposite force comes from the flow field pressure of the cylinder fluid.

In terms of the control fluid 1, according to Newton's second law, there is:

$$
m \ddot{y}=-k y-F^{\prime}{ }_{S P}+F_{f} \cdot
$$

When the conical valve port is opened, the force of the cylinder fluid is shown in Fig. (3). For the cylinder fluid, the Reynolds transport theorem gives the equation (5):

$$
\rho L \frac{\partial Q}{\partial t}+\rho \frac{Q^{2}}{A} \cos \theta=P A_{s}-F_{f},
$$

where: $A_{s}=\pi D^{2} / 4$. The cylinder fluid is subjected to the reaction force and the flow field pressure acting on the cone body. Due to $y / D \ll 1$, the counteracting effect of the flow field pressure on the cylinder fluid can be ignored. $F_{f}=-F_{t}-F_{s}+F_{p}$, where: $F_{t}=\rho L \frac{\partial Q}{\partial t}, F_{p}=P A_{s}$, $F_{s}=\rho \frac{Q^{2}}{A} \cos \theta$.

For the control fluid 2, the pressure flow relationship (Eq. (6)) expressed in terms of the bulk elastic modulus of the fluid is as follows:

$$
\frac{d P}{d t}=\frac{\beta}{V}\left(Q_{0}-Q\right)
$$

By integrating Eqs. (2) - (6), the nonlinear equation of motion of the conical valve body can be obtained:

$$
\begin{aligned}
& m \ddot{y}+k y=A_{S}\left(P-P_{0}\right)- \\
& -\rho L C_{d} \sqrt{2 / \rho P} \pi\left(\begin{array}{l}
D(\sin \theta) \dot{y} \\
+2(\cos \theta)\left(\sin ^{2} \theta\right) y \dot{y}
\end{array}\right)+ \\
& +\rho L \frac{1}{2} \pi\left(\begin{array}{l}
D(\sin \theta) y \\
+(\cos \theta)(\sin \theta D) \mathrm{y}^{2}
\end{array}\right) C_{d} \sqrt{\frac{2}{\rho P}} \dot{P}- \\
& -2 \pi\left(\begin{array}{l}
D(\sin \theta) \mathrm{y} \\
+(\cos \theta)\left(\sin ^{2} \theta\right) \mathrm{y}^{2}
\end{array}\right) \mathrm{C}_{d}^{2} P(\cos \theta) .
\end{aligned}
$$

Testing procedure of $J-R$ curve is described in the American standard ASTM E1152-87 [1]. In the majority of tests compact specimens $C(T)$ for tension or $B(T)$ for bending are applied. Compact specimens (Fig. 1) of different sizes are applied. The standard offers the following thickness of specimens: $1 / 2 T, 1 T, 2 T$ and $4 T$, where $T=25.4 \mathrm{~mm}$. The specimens have three basic sizes: length of a crack $a$, thickness $B$ and width $W$. In many cases there are accepted $W=2 B$ and $a / W>0.5$. Basic sizes of specimen's $B$ and $W$ - $a$ should exceed the size of plastic zone in advance of a developing crack minimum 50 times, otherwise the incorrect characteristics of fracture toughness will be received. Sizes of the test specimens depend on the thickness of material; from which they are made. Specimens of the size $1 / 2 T$ and $1 T$ have been used in our test, because the diameter of steam pipes.

Factor of load asymmetry in cycle during precracking should not exceed $r \leq 0.1$ and the length of a crack should not be less than $5 \%$ from $a_{0}$, but not less than $1.3 \mathrm{~mm}$. Beside the definition of $J-R$ by the method of a compliance requires to observe condition $0.5<a_{0} / W<0.75$, where: $a_{0}$ is the distance from loading line up to the top of a crack. At $a_{0} / W<0.5$ the method of compliance loses sensitivity, and at $a_{0} / W>0.75$ the plastic zone will be much more increased and becomes too large. So, the ratio $a_{0} / W$ in our experiments varied within the limits $0.5-0.75$. 


\section{Overflow stability conditions}

Ignoring the high order term (since $y / D \ll 1$ ), we linearize Eq. (7) to obtain the linearized differential equation for the conical core and convert it to the Laplace form, as shown in Eq. (8).

$$
\begin{aligned}
& \left(M_{\text {eff }} \cdot s^{2}+C_{\text {eff }} \cdot s+K_{\text {eff }}\right) Y(s)= \\
& =A_{\text {eff }} P(s)-A_{\text {eff }} P_{0}+K_{\text {eff }} \cdot y_{0} .
\end{aligned}
$$

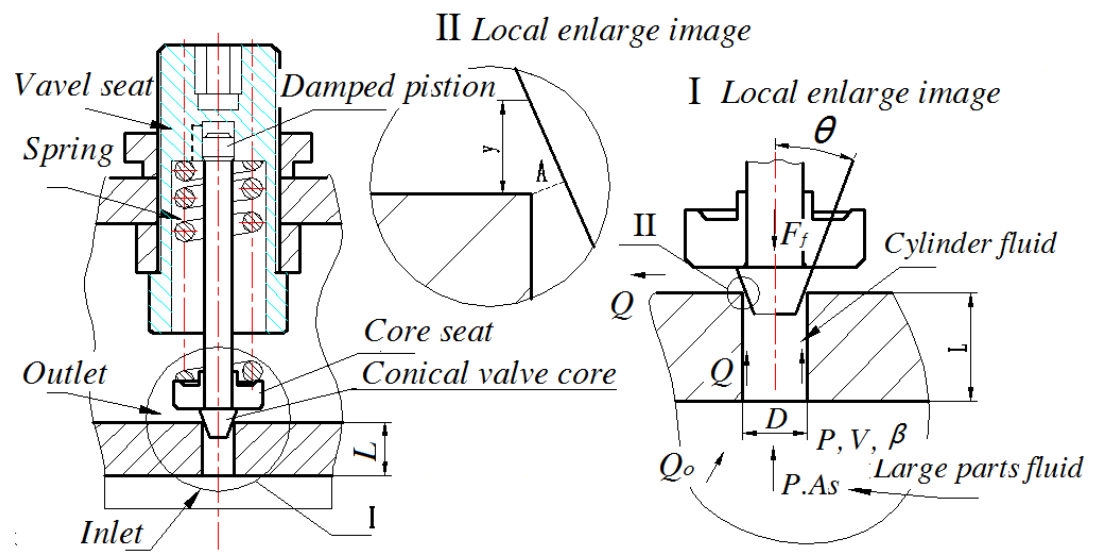

Fig. 1 Structure and parameters of cone relief valve
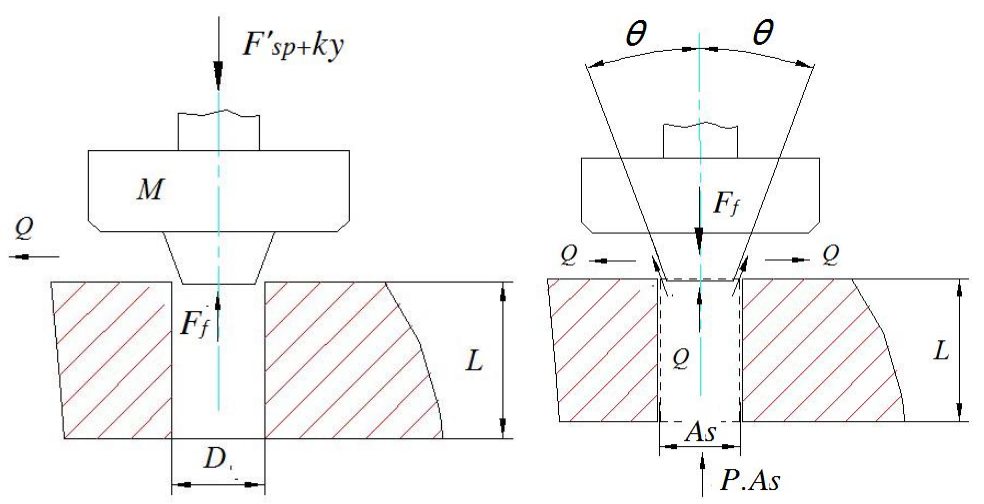

Fig. 2 Free state and Force diagram of the valve obtained.

Similarly, the Laplace's formula of Eq. (6) can be

$$
\begin{aligned}
& s P(s)=-\frac{\beta}{V} K_{q}\left(Y(s)-y_{0}\right)- \\
& -\frac{\beta}{V} K_{c}\left(P(s)-P_{0}\right) . \\
& K_{e f f} k+K_{f q}-\rho L K_{c} K_{q} \beta / V, \\
& F_{d}=K_{e f f} y_{0}+A_{e f f}\left(P-P_{0}\right), \\
& A_{e f f}=A_{s}-K_{f c} y_{0}+\rho L K_{c}^{2} \beta / V, \\
& K_{f c}=2 \pi D(\sin \theta) y_{0} C_{d}^{2}(\cos \theta), \\
& K_{f q} f=2 \pi D(\sin \theta) P_{0} C_{d}^{2}(\cos \theta) .
\end{aligned}
$$

The block diagrams of Eqs. (8) and (9) are connected in the direction of transfer to give a dynamic block diagram of the relief valve system. As shown in Fig. 3.

From Fig. 3 we can see that the system consists of two layers, one of which comes from the fluid pressure equation.

By integrating Eqs. (8) and (9), the Laplace formula of conical valve core displacement as shown in Eq. (10).
The denominator of Eq. (10) is the cubic term. This cubic term is the characteristic equation of the conical relief valve and will be used to establish the valve's stable overflow condition. This cubic item can be represented by the general formula (Eq. (11)).

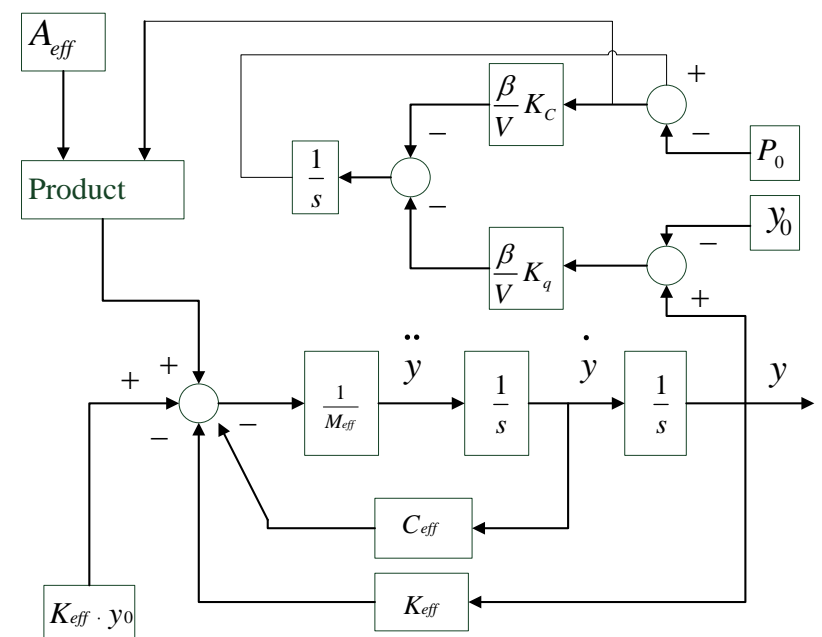

Fig. 3 Working analysis principle diagram of this valve 


$$
\begin{aligned}
& {\left[\left(\frac{V}{\beta} s+K_{c}\right)\left(K_{e f f} \cdot y_{0}-A_{e f f} P_{0}\right)+\right]} \\
& Y(s)=\frac{\left[+K_{q} A_{e f f} f \cdot y_{0}+K_{c} A_{e f f} P_{0}\right]}{\left[M_{e f f} \frac{V}{\beta} s^{3}+\left[C_{e f f} f \frac{V}{\beta}+M_{e f f} K_{c}\right] s^{2}+\right]} \\
& +\left[K_{\text {eff }} f \frac{V}{\beta}+C_{\text {eff }} K_{c}\right] s+ \\
& +\left(K_{e f f} K_{c}+A_{e f f} K_{q}\right) \\
& s^{3}+\lambda_{2} s^{2}+\lambda_{1} s+\lambda_{0}=0 . \\
& \text { There is: } \lambda_{2}=\frac{\rho L K_{q}}{m}+K_{c} \frac{\beta}{V} \text {, } \\
& \lambda_{1}=\frac{\left(k+K_{f c}-\rho L K_{c} K_{q} \frac{\beta}{V}\right) / m+\rho L K_{q} K_{c} \beta}{m V}, \\
& \lambda_{0}=\left(k+K_{f c}-\rho L K_{c} K_{q} \frac{\beta}{V}\right) K_{c} \frac{\beta}{m V}+ \\
& +\left(A_{s}-K_{f c}+\rho L K_{c}^{2} \beta / V\right) K_{q} \frac{\beta}{m V}
\end{aligned}
$$

Eq. (12) shows its Rausian matrix.

$$
\begin{array}{cccc}
s^{3}: & 1 & \lambda_{1} & 0 \\
s^{2}: & \lambda_{2} & \lambda_{0} & \\
s^{1}: & \left(\lambda_{2} \lambda_{1}-\lambda_{0}\right) / \lambda_{2} & 0 \\
s^{0}: & \lambda_{0} &
\end{array} .
$$

To stabilize the system, the first column elements in this Rausian matrix should be greater than zero. That is, when $\lambda_{2} \lambda_{1} / \lambda_{0}>1$, the Rausian matrix is stable. Substituting the parameters into the post-order and ignoring the higher order terms will result in a stable condition: $\Lambda=\frac{\rho L V\left(k+K_{f q}\right)}{m \beta\left(A_{s}-K_{f c}\right)}>1 . \Lambda$ is called stability factor.

\section{Model and model analysis}

The conical relief valve (shown in Fig. 1) uses the structural parameters and working conditions as shown in Table 1. The model of the relief valve developed based on the analysis block diagram of the conical valve port depicted in Fig. 3 is shown in Fig. 4.

Conical relief valve system parameters used are shown in Table 1.

When the hydraulic pressure is greater than the spring force, the conical valve port opens, and the relief valve begins to overflow. The effectiveness of the model is verified by taking the overflow flow and the hydraulic force on the conical valve core as an example.

Fig. 5 shows that the valve core displacement remains unchanged at the initial steady state position $y_{0}=0.4 \mathrm{~mm}$. By changing load pressures, the other parameters given in Table 1 are unchanged, and the curves of the relationship between overflow flow and pressure under different pressures are obtained. The solid line is the model analysis data, and the cross line is the experimental data (experimental model see Ref. [13]).
Table 1

Parameters of conical relief

\begin{tabular}{|c|c|c|}
\hline Symbol & Numerical value & Units \\
\hline$D$ & 8 & $\mathrm{~mm}$ \\
\hline$k$ & 10 & $\mathrm{~N} / \mathrm{mm}$ \\
\hline$L$ & 12 & $\mathrm{~mm}$ \\
\hline$m$ & 5 & $\mathrm{~g}$ \\
\hline$V$ & $10^{6}$ & $\mathrm{~mm}^{3}$ \\
\hline$\theta$ & 45 & $\mathrm{Deg}$ \\
\hline$C_{d}$ & 0.62 & \\
\hline$P_{0}$ & 20 & $\mathrm{MPa}$ \\
\hline$\beta$ & 1.2 & $\mathrm{GPa}$ \\
\hline$\rho$ & 850 & $\mathrm{~kg} / \mathrm{m}^{3}$ \\
\hline$y_{0}$ & 0.4 & $\mathrm{~mm}$ \\
\hline
\end{tabular}

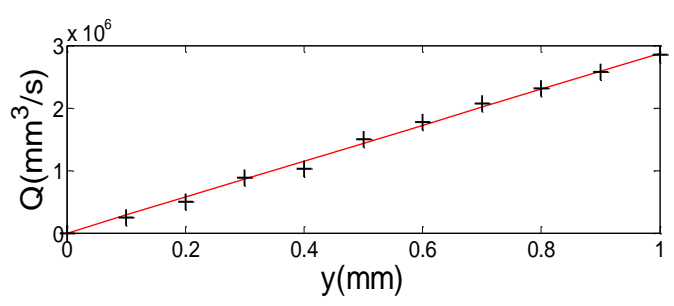

Fig. 5 Flow - displacement $y_{0}=0.4 \mathrm{~mm}$

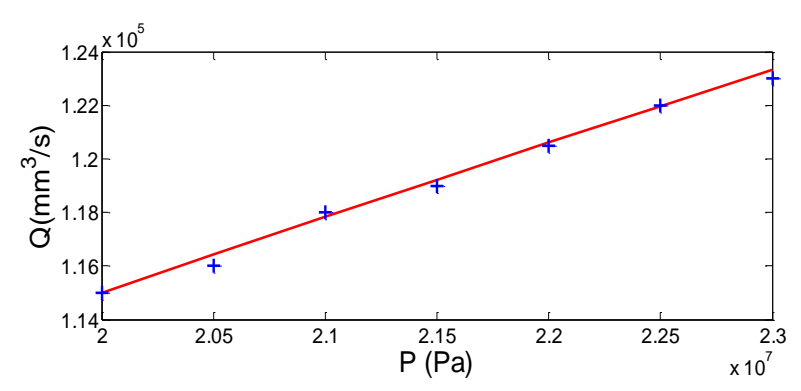

Fig. 6 Flow - pressure $P_{0}=20 \mathrm{MPa}$

Fig. 6 shows that the valve core displacement remains at the initial steady state position $P_{0}=20 \mathrm{MPa}$.

Changing the position of the valve core while the other parameters given in Table 1 are unchanged, the displacement curves of the relief valve core under different displacements are obtained.

The relationship curves shown in Figs. 5 and 6 indicate that the error of the model built is too small to affect the stability of the predicted overflow. The model can be used to analyze the overflow dynamic characteristics of the conical relief valve.

Fig. 7 shows that the valve core displacement remains unchanged at the initial steady state position $y_{0}=0.4 \mathrm{~mm}$. Under different load pressures while other parameters given in Table 1 were unchanged, the relationship between the steady-state hydraulic power and pressure under different pressures can be obtained.

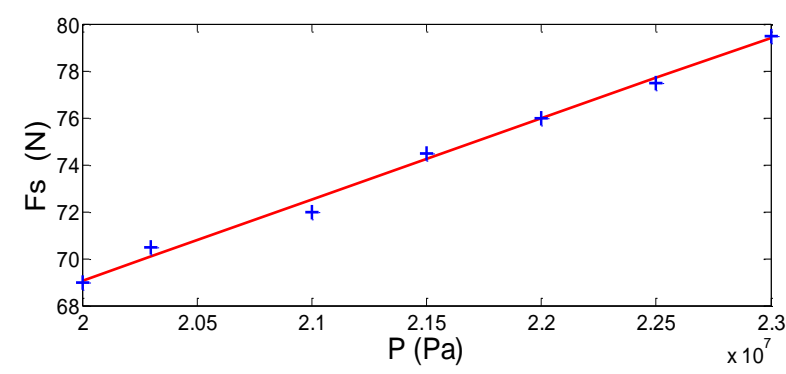

Fig. 7 Steady-state hydraulic power and pressure $y_{0}=0.4 \mathrm{~mm}$ 


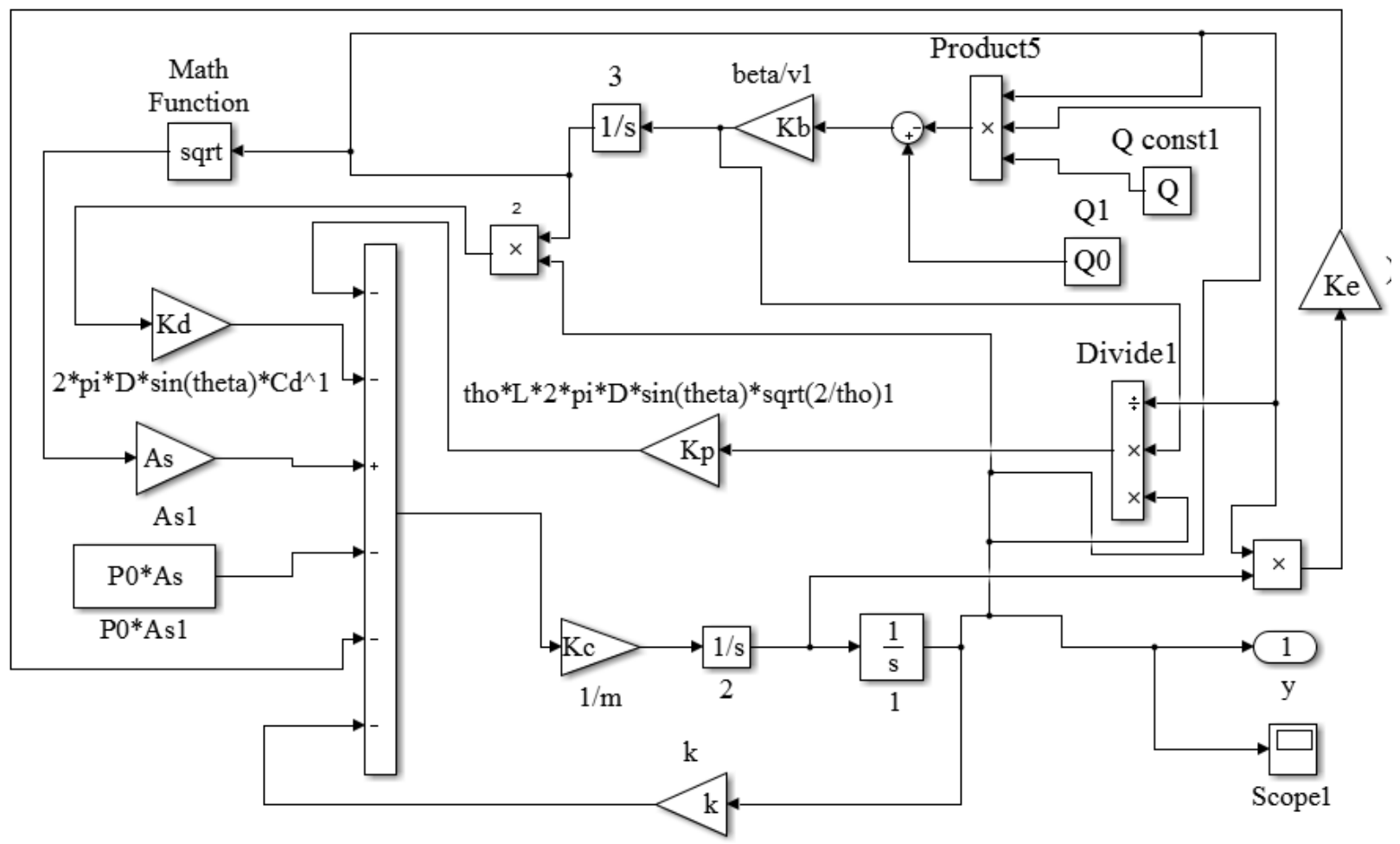

Fig. 4 Analysis process of this valve

Fig. 8 shows that the valve core displacement remains at the initial steady state position $P_{0}=20 \mathrm{MPa}$.

Changing the position of the valve core while the other parameters given in Table 1 are unchanged, the displacement curves of the relief valve core under different displacements are obtained.

It can be seen from the relation curves reflected in Figs. 7 and 8 that the error of the established model is too small to affect the problem of predicting overflow stability. The model built can be used to analyze the relief dynamics of a conical relief valve.

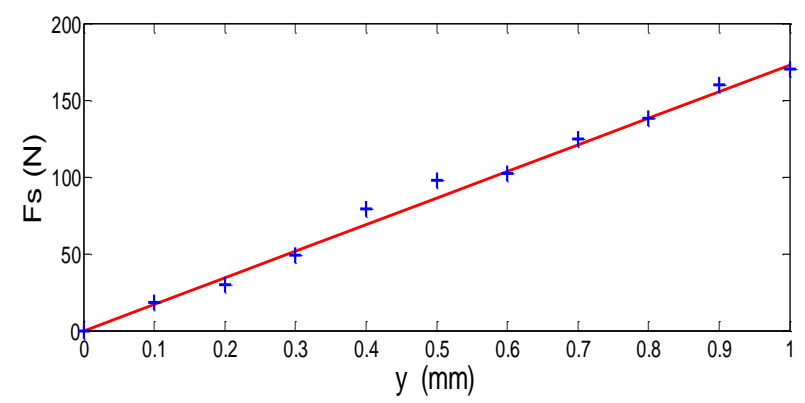

Fig. 8 Steady-state hydraulic power and displacement $P_{0}=20 \mathrm{MPa}$

\section{Overflow dynamic characteristics and stability analysis}

The influence of the structural parameters of the conical relief valve on the stability of the system is analyzed using the $L / D$ parameters. The degree of influence of other structural parameters is discussed through sensitivity analysis.

$L / D$ is the ratio of the length to the diameter of the cylindrical fluid 1. Fig. 9 compares the fluctuations of the hydraulic force of the relief valve during operation when the
$L / D$ parameters are respectively $1.5,7$, and 10 , which reflects the influence of the $L / D$ parameter change on the hydraulic force. When the parameter $L / D$ is 1.5 , the stability factor $\Lambda$ is 6.1805. From Fig. 9 it can be seen that the system is finally stable, although there is a significant range of fluctuation before and after $0.0003 \mathrm{~s}$; when the parameter $L / D$ is 4 , the stability coefficient $\Lambda$ is 16.4813 . At this time, the system oscillation is slightly more stable than when $L / D$ is 1.5 . After $0.00008 \mathrm{~s}$, the hydraulic power curve changes approximately linearly. The system stability is better than when $L / D$ is 1.5 ; when the parameter $L / D$ is 6 , the stability factor $\Lambda$ is 24.7220 , and the system stability is better. After several verifications, $L / D$ greater than 4 can be used to predict that the system's hydrodynamic output can be more stable.

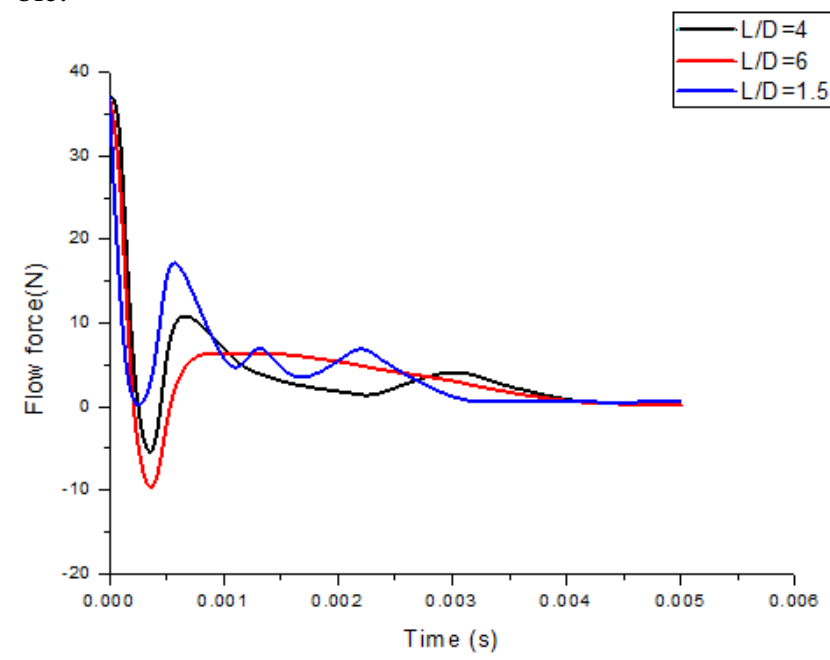

Fig. $9 L / D$ parameters on hydrodynamic forces

Fig. 10 is used to predict the position of the conical valve core in the dynamic process of conical relief valve overflow. After several experimental studies, it is found that 
when the $L / D$ ratio is less than 4 , the position change of the poppet during overflowing is relatively large; when the $L / D$ is greater than 4 , and the greater the value, the change trend of the poppet's displacement tends to change linearly in a first-order manner, and the system has a better stable overflow capacity.

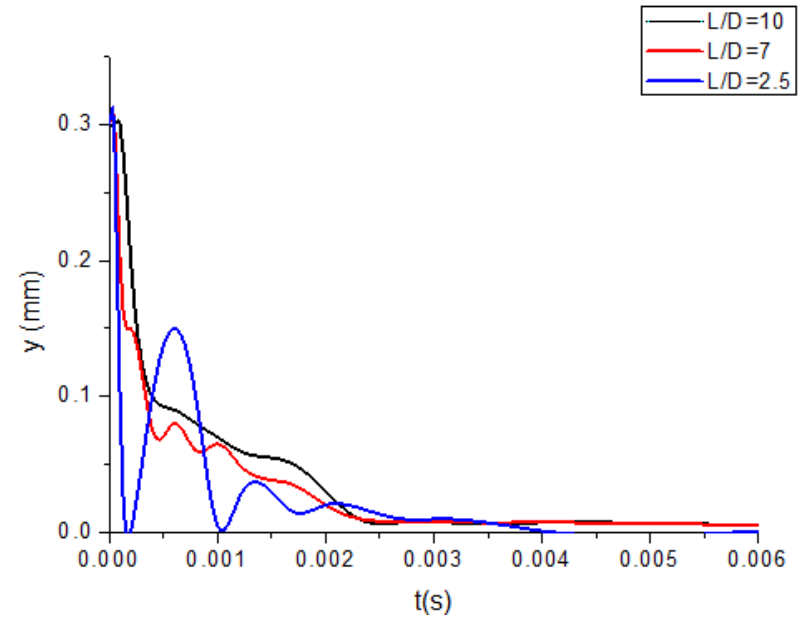

Fig. $10 L / D$ parameters on displacement

Figs.11-12 show how the system approaches the unstable output by changing the size of the cylinder fluid.

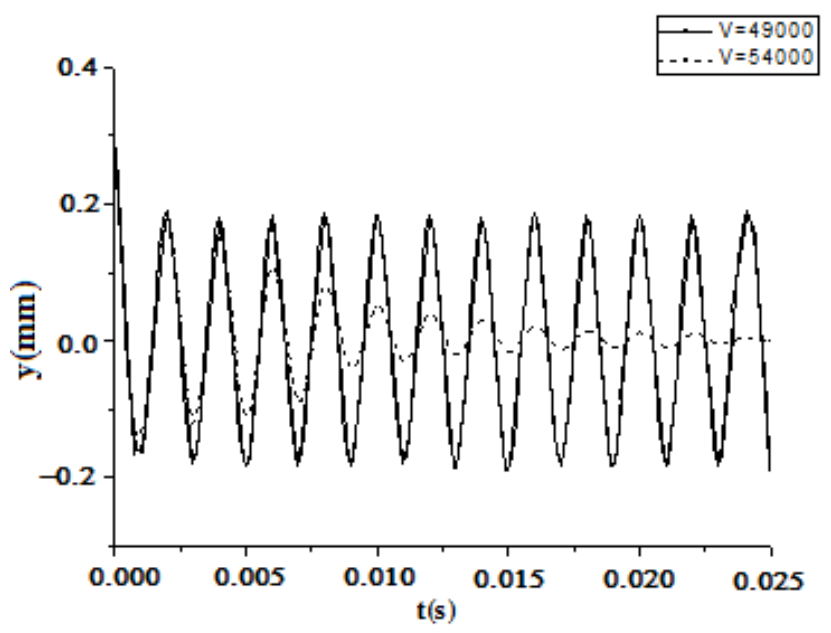

Fig. 11 Curves of displace-time $V=54000,49000 \mathrm{~mm}^{3}$

In Fig. 11, $V=54000,49000 \mathrm{~mm}^{3}$. At this time, $\Lambda$ is 1.0976 . After repeated diagnosis, the system finally stabilizes. From the stability determination condition, it can also be known that $\Lambda$ is greater than 1 and the system will have a stable output; in Fig. 12, $V$ is reduced to 49000 and is equal to 1 , the system has been in small fluctuations, showing critical stability. This also coincides with the stability determination condition. $V$ is 46000 and is equal to 0.9247 . The system vibrates more and more violently with time. At this time, $\Lambda$ is less than 1 .

From the stability conditions, the parameters $L, D$, $K, m, V$ and $\beta$ all affect the stability of the system. The degree of influence of these parameters can be effectively evaluated by sensitivity analysis.

The higher the stability factor, the more stable the system. In order to effectively assess the influence of design parameters on the stability of the system, a sensitivity analysis is performed.

$$
b=\left[\begin{array}{l}
D \\
k \\
L \\
m \\
V \\
\beta
\end{array}\right], \Delta \Lambda=\Lambda(b i)-\Lambda(b i+\Delta b i),
$$

$\Delta b i=0.1 b i$,

$\Delta \Lambda=\Lambda(b i)-\Lambda(b i+\Delta b i)$.

By substituting the parameters shown in Table 1 into Eq. (12), there is:

$$
\Delta \Lambda=\left[\begin{array}{l}
1.0727 \\
-0.0338 \\
-0.6185 \\
0.5619 \\
-0.6185 \\
0.5619
\end{array}\right] .
$$

From the result of Eq. 13, it can be seen that the change of the design parameter $D$ has the greatest effect on the stability of the system. To a certain extent, the stability of the system depends on the energy storage level of the components, such as the compressibility of the spring. The length $L$ of the cylinder fluid affects the compressibility of the cylinder fluid and changes its energy storage level. Shortening $L$ causes the system stability coefficient to become smaller and the system to become unstable. The smaller the $D$ is, the worse the stability of the system is, and the $\beta$ will increase, thus, decreasing system stability.

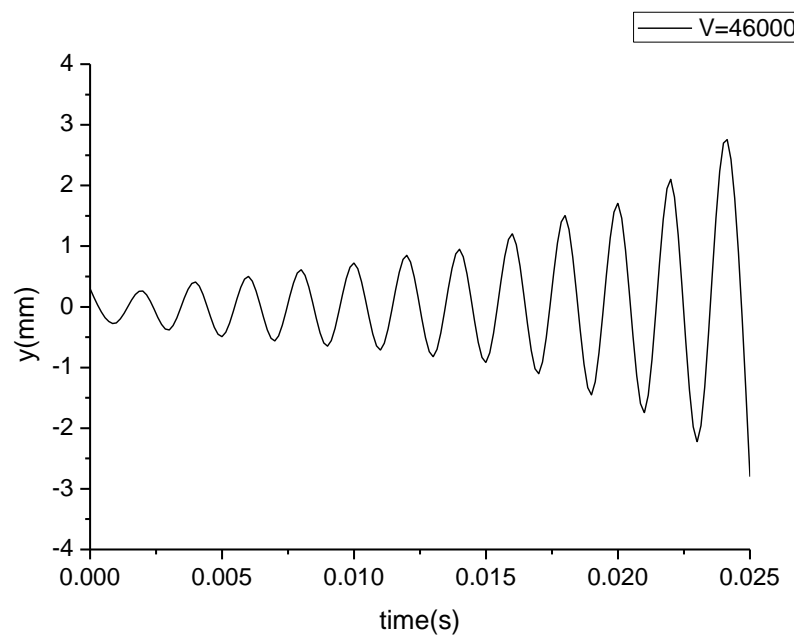

Fig. 12 Curve of displace-time $V=46000 \mathrm{~mm}^{3}$

\section{Conclusions}

1. The fluctuations of the hydraulic force of the relief valve are compared when the $L / D$ parameters are respectively $1.5,7$, and 10 . After several verifications, $L / D$ greater than 4 can be used to predict that the system's hydrodynamic output can be more stable. The larger the $L / D$ value, the 
higher the stability coefficient and the more stable the system.

2. The higher the stability factor, the more stable the system. The degree of influence of these parameters $L$, $D, K, m$ and $V$ can be effectively evaluated by sensitivity analysis of factor $\Lambda$. Design parameter $D$ has the greatest effect on the stability of the system.

\section{Acknowledge}

This work was supported in part by The National Natural Science Fund of China, University of Jiangsu Natural Science Foundation, and SANY Co., Ltd. in Jiangsu. Lecturer, Support Fund Nos. 51505211, 51505212, 16KJB460012.

\section{References}

1. Li, Y.; Jiao, Z.; Wu, S. 2013. Flow characteristics analysis and optimization design of high frequency reciprocation pump applying check valve to rectification, Journal of Mechanical Engineering 49(14):154-163. https://doi.org/10.3901/JME.2013.14.154.

2. Massimo, R.; Giorgio, A. 2017. Comparison of analytical and numerical methods for the evaluation of the flow forces in conical poppet valves with direct and reverse flow, Energy Procedia 126:1107-1114. https://doi.org/10.1016/j.egypro.2017.08.261.

3. Bazsó, C.; Hős, C. J. 2013. An experimental study on the stability of a direct spring loaded poppet relief valve, Journal of Fluids and Structures 42:456-465. https://doi.org/10.1016/j.jfluidstructs.2013.08.008.

4. Noah, D. M.; Shusen, Z. 2011, The theoretical bandwidth frequency of a three-way hydro-mechanical valve. Proceedings of the ASME 2011 Dynamic Systems and Control Conference 2:335-342. https://doi.org/10.1115/DSCC2011-5900.

5. Ji, C.; Wang, J.; Mo, G.; Zou, J.; et al. 2018. Instability of a poppet valve: interaction of axial vibration and lateral vibration, International Journal of Advanced Manufacturing Technology 94(9-12):3065-3074. https://doi.org/10.1007/s00170-016-9305-x.

6. Abolghasemzadeh, M.; Khaleghinia, J.; Kordani, N.; Sadough Vanini, A. 2013. Simulation of critical J-integral in functionally graded steels components weakened by $\mathrm{U}$ and blunt $\mathrm{V}$-shape notches under Charpy test, Computational materials science 70:123-132. https://doi.org/10.1016/j.commatsci.2013.01.001.

7. Manring, N. D.; Zhang, S. 2012. Pressure transient flow forces for hydraulic spool valves. Journal of Dynamic Systems, Measurement and Control, Transactions of the ASME 134(3): 0345011-0345014.

https://doi.org/10.1115/1.4005506.

8. Amirante, R.; Distaso, E.; Tamburrano, P. R. 2014. Experimental and numerical analysis of cavitation in hydraulic proportional directional valves, Energy Conversion and Management 87:208-219.

https://doi.org/10.1016/j.enconman.2014.07.031.

9. Jia, W.; Yin, C.; Zhu, D.; Jiang, X. 2016. Influence of rectangular grooved labyrinth seal on the flow characteristics of valve core, Journal of Computational and Theoretical Nanoscience 13 (14):2376-2381. https://doi.org/10.1166/jctn.2016.4589.
10. Miana, M. J.; Núñez, J. L.; Pütz, T.; Valdés, J. R. 2008. Reduced order model for estimation of fluid flow and flow forces in hydraulic proportional valves, Energy Conversion and Management 49(6):1517-1529. https://doi.org/10.1016/j.enconman.2007.12.010.

11. Makaryants, M. 2017. Fatigue failure mechanisms of a pressure relief valve, Journal of Loss Prevention in the Process Industries 48: 1-13. https://doi.org/10.1016/j.jlp.2017.03.025.

12. Rafiee, S.E.; Sadeghiazad, M.M. 2017. Experimental and 3D CFD investigation on heat transfer and energy separation inside a counter flow vortex tube using different shapes of hot control valves, Applied Thermal Engineering 110(5): 648-664. https://doi.org/10.1016/j.aplthermaleng.2016.08.166.

13. Ye, Y.; Yin, C.; Li, X.; et al. 2014. Effects of groove shape of notch on the flow characteristics of spool valve, Energy Conversion and Management 86: 1091-1101. https://doi.org/10.1016/j.enconman.2014.06.081.

\section{W.H. Jia, C.B Yin}

\section{DYNAMIC CHARACTERISTICS AND STABILITY ANALYSIS OF CONICAL RELIEF VALVE}

\section{S u m m a r y}

The overflow rate of poppet relief valve is established, the dynamics characteristics of poppet relief valve which contains transient flow force and steady flow force is established. Based on this point, the stability conditions of poppet relief valve system are derived using Routh-Hurmitz method. The effect of the design parameters of relief valve on the dynamic characteristics of poppet valve system is analyzed. Using sensitivity analysis, the effects of parameters of the most significant is obtained, that is diameter D of liquid flow cylinder fluid. The results showed that, the established model can largely capture the dynamic characteristics of the relief valve system, the established stability condition can be used as a favorable basis for the design of valve.

Keywords: overflow stability condition, flow model; Routh matrix, sensitivity analysis.

Received September 03, 2018 Accepted February 15, 2019 